\title{
More Reforms, Less Innovation? \\ The Impact of Structural Reform Histories on Innovation- Oriented Cultures in Public Organizations
}

\begin{abstract}
The environments of public organizations have become substantially volatile due to economic and societal changes, requiring organizations to continuously adapt and to develop an innovation-oriented culture. In response to the multitude of challenges posed by this volatile environment, politicians in inter alia the executive and parliament impose structural reforms upon public organizations, implying that these organizations might be confronted with a series of structural reforms over their lifetime. This paper advances that a history of repeated and frequent structural reforms, irrespective of the underlying drivers of these reforms, has a negative effect on the innovation-orientedness of the organizational culture. We explore the link between an organization's history of structural reforms and the degree to which the culture within these organizations is innovation-oriented. Results indicate that organizational turmoil generated by repeated structural reforms reduces innovativeness, and suggest that too many structural reforms imposed in a too short time-span will have detrimental side-effects.
\end{abstract}

Keywords: organizational culture, structural reform history, innovation 


\section{Introduction}

Rapid social developments, economic pressures, political changes, and increasing demands on public sector performance have made the environment in which public organizations operate substantially volatile. This requires organizations to continuously adapt in response to evolving circumstances and public demands (Damanpour, 1991; Damanpour \& Gopalakrishnan, 1998; Valle, 1999). Public services have to be altered, new measures have to be prepared and operational action needs to be reprioritized to address evolving situations. A failure of a public organization to innovate in the context of turbulent environmental changes implies its environmental fit should gradually be reduced (Damanpour \& Gopalakrishnan, 1998; Kontoghiorghes, Awbrey \& Feurig, 2005), which will detrimentally affect its performance. Consequently, public organizations have to be creative and innovative (Pennings, 1987; Borins, 2001; Damanpour \& Schneider, 2009; Frambach \& Schillewaert, 2002; Nyhan, 2000; Walker \& Boyne, 2006), meaning that an innovation-oriented organizational culture is an important attribute to help ensure that an organization continues to adapt to its turbulent environment (Osborne \& Brown, 2011; Martins \& Terblanche, 2003; Damanpour, 1991; Hogan $\&$ Coote, 2014).

Simultaneously, in response to the multitude of challenges posed by this volatile environment, politicians in the executive and parliament do not only launch new policies and management instruments, but also impose structural reforms upon public organizations. Such structural reforms might be part of government-wide reform programs, or more geared towards organizations in specific sectors, with specific legal forms or tasks. Through these structural reforms, organizations may receive or lose tasks, absorb or secede units from/to other organizations, change legal forms, be placed closer or further from the minister in terms of autonomy and control, or even undergo privatization (MacCarthaigh \& Roness, 2012; Lægreid et al., 2010). 
Some of these reforms have the aim to make the organizations more responsive and adaptable to their environment and hence increase their innovativeness (Walker \& Boyne, 2006; Pollitt \& Dan, 2011). Other structural reforms might be motivated on other grounds, like political favour-granting and package deals (logrolling) or isomorphic behaviour. However, irrespective of their underlying motivations and intentions, research in organizational psychology posits that structural reforms will incur disruptive side-effects such as stress and anxiety within public organizations (De Vries, 2013; Marks \& Mirvis, 1997; Pollitt, 2007; McMurray, 2010; Amiot et al., 2006; Grunberg, Moore \& Greenberg, 2008; Seo \& Hill, 2005). Given the potential occurrence of these side-effects, it is important to deepen our understanding of the impact that long-term reform trajectories may have on public sector organizations. Therefore, this paper tests the effects of multiple structural reforms on the organizational culture of the public organizations subjected to them, and more in particular on the extent to which this organizational culture is oriented towards innovation. In this context, structural reforms are defined as those reforms that change the organizational boundaries in terms of units included, change the tasks attributed to the organization and/or change the structural embeddedness of the organization in the wider public sector (i.e. its legal form and ministerial portfolio) (see e.g. MacCarthaigh \& Roness, 2012; Lægreid et al., 2010).

More specifically, we expect that as heightened levels of stress and uncertainty persist within organizations that undergo such sequences of structural reforms, they may move towards a more rigid, risk-averse and centralized state (Staw, Sandelands \& Dutton, 1981; Dutton, 1986; Olson \& Sexton, 2009). In turn, the stress and uncertainty caused by frequent structural reform may detrimentally affect the innovative behavior of the organization as risk taking, autonomy and support for innovative action become reduced (Borins, 2001; Mintzberg, 1983; Damanpour, 1991; Voorberg, Bekkers \& Tummers, 2015). Although the side-effects of singleevent structural reforms should gradually dissipate over time (Seo \& Hill, 2005; Moore, 
Grunberg \& Greenberg, 2004; Grunberg, Moore \& Greenberg, 2008), we argue that organizations in highly volatile environments may not have the time to recuperate from past structural reforms before a new set of reforms is introduced (Pollitt, 2007; De Vries, 2013). In these instances, the positive effects of a single structural reform on innovativeness (see on this topic e.g. Wynen et al., 2014; Dan \& Pollitt, 2015) may be outweighed by the continued stress generated by a sequence of multiple structural reforms within the organization. Thus, although a turbulent environment requires a high level of innovation and adaptation, the stress and uncertainty produced by frequent and severe structural reform may paradoxically be expected to reduce the level of innovation-orientedness of a public organization.

We explore this topic through a quantitative analysis of the structural reform histories of 45 Flemish public organizations. Flanders is one of the autonomous regions of the Belgian federal system with its own parliament, cabinet and public administration, consisting of departments and agencies, and the region can be considered a full-fledged state for the competences under its remit. As such, the Flemish government has been confronted with various social and economic developments, including the 2008 financial crisis and the 2015 refugee crisis, resulting in both policy and structural changes. Notable international reform trends have manifested themselves on the Flemish level as well, with for instance the 20032006 period being defined by far-reaching and government-wide reforms inspired by the New Public Management (NPM) doctrine (Verschuere \& Barbieri, 2009) and the 2008-2015 period involving structural reforms inspired by the post-NPM doctrine (e.g. Roness et al., 2008) as well as by austerity programs (Vis, Van Kersbergen \& Hylands, 2011). The simultaneous presence of these processes implies that various Flemish public organizations have undergone frequent structural reforms in the past decades. The Flemish public sector is therefore a suitable setting for an investigation into the effects of organizational reform histories on innovationoriented culture. 
The remainder of the paper is organized as follows. The next section discusses the importance of innovation-oriented culture and the effect of an organization's reform history in more detail. The utilized data is discussed in section 3. Section 4 presents an in-depth analyses of the examined relationship, and section 5 concludes.

\section{The importance of organizational culture and the link with an organization's history of reforms}

Management literature on innovation argues that organizations in changing and turbulent environments require an organizational culture that stimulates innovativeness, change and that provides space for employees to take risks (Osborne \& Brown, 2011; Damanpour, 1991; Dorabjee, Lumley \& Cartwright, 1998). In the private sector, innovation allows companies to pre-empt rivals and changing environments in order to remain competitive (e.g. Damanpour, 1991). While the pressure of competition is often absent in the public sector, environmental factors such as rapid technological change, economic fluctuations, globalization and social change nonetheless confront public organizations with changing and tumultuous sets of demands that require organizational adaptation (Parry \& Proctor-Thomson, 2003; Hacker, 2004). A service organization may for instance have to expand its services to new groups of beneficiaries, evolve new services to adapt to changing circumstances in its task environment, develop its existing services to better accommodate its beneficiaries, or even design a total overhaul of its services and interpretation of the relevant target group (Osborne, 1998). Thus, developing cultures that stimulate innovation and flexibility is important to adapt services and processes to the organizational environment and to sustain or increase performance (Damanpour, 1991).

The question is, however, to what extent the repeated imposition of structural reform programs is conducive to the development of innovation-oriented cultures. Culture is 
considered a relatively stable factor in organizations, which is difficult to mold through rational change initiatives. Indeed, Quirke (1995) argues that culture can sometimes impede perspective changes, noting that "the force of the culture is for the status quo, culture is the means by which we bring stability to the threat of change". However, while culture is difficult to steer in a desired direction through top-down change initiatives, this is not to say that culture remains static after its initial development. Instead, organizational cultures are dynamic in the long-term, gradually undergoing change as external and internal factors emerge to shape it (for an overview of various factors, see Lægreid, Roness \& Verhoest, 2011). Organizations may for instance gradually incorporate the best-practices and views of similar entities through mimetic and normative isomorphism, with the adoption of these external items contributing to a steady adaptation of an organization's culture (e.g. DiMaggio \& Powell, 1983; Manville et al., 2016).

Following Schein (2000, p.8), we have therefore opted to define culture as follows: "Culture is a pattern of shared basic assumptions that the group learned as it solved it problems of external adaptation and internal integration that has worked well enough to be considered valid and, therefore, to be taught to new members as the correct way to perceive, think, and feel in relation to those problems." This interpretation of culture implies that external reforms hold the potential to influence culture in desired directions to some extent (see e.g. Wynen \& Verhoest, 2015), but that these reforms may also have unintended consequences when the impact of reforms is filtered through the internal perceptions of the organization's leadership and employees. Frequent and severe reforms of the organization's structure may be perceived as threatening, stimulating the gradual development of a culture leaning towards centralization, risk-averseness and rigidity. The paradox is that while the ongoing reforms thus induce a rigid and top-down culture, the literature on innovation indicates that decentralization, autonomy and a supporting internal attitude towards innovations and risk- 
taking are important factors in stimulating innovative behavior (Borins, 2001; Osborne \& Brown, 2011; Voorberg, Bekkers \& Tummers, 2015; De Vries, Bekkers \& Tummers, 2016).

To understand why large amounts of structural reforms implemented in quick secession can be detrimental to the development of an innovation-oriented culture, the response of organizations to the challenges that reforms pose must first be examined. The threat-rigidity effect explored by Staw, Sandelands \& Dutton (1981) provides a useful starting point. This model predicts both individual as well as organization and group-level effects. On the organizational and group levels, Staw, Sandelands \& Dutton (1981) argue that as threatening situations demand urgent action and endanger the legitimacy of organizational leadership, there will be a tendency to reserve decision-making to a small set of central leaders. Moreover, these leaders will opt to introduce more central steering, in order to prevent lacking coordination and mistakes on the decentral level that would further threaten the organization (see also Mishra, 1996). Dutton (1986) subsequently tested the centralization link in the context of an organizational crisis and found that crisis issues were indeed related to increased monitoring and control initiated by top-level management, and that lower-level echelons were excluded from decision-making by excluding them from communication on the issue. More recent research in various areas points to similar effects in organizations faced with a substantial threat (Daly et al. 2011; Olson \& Sexton, 2009). Thus, in the face of threatening, uncertain and hostile environments, the literature on the threat-rigidity effect suggests that organizations will show a reflex towards greater centralization.

Public management literature provides strong indications that successive structural reforms constitute situations that could cause the threat-rigidity effect. It has been argued that public managers faced with implementing successive restructurings are forced to cope with continuously changing external demands from political superiors, for instance through new sets of performance indicators and performance contracts (Pollitt, 2007; McMurray, 2010). In 
addition to these new output requirements, the political superior itself may change due to a reform, forcing senior managers of the involved organisation to rebuild social ties and trust with the new principal of the organization and to reaffirm that they lead the organization effectively (Pollitt, 2007; De Vries, 2013). These external demands are moreover accompanied by internal demands for the managers to lead the organization through the reform as well as possible - for instance by appropriately redeveloping the organization's services and management techniques post-reform (see e.g. Manville et al., 2016).

As many structural reforms leave some leeway for organizations to decide on the steps necessary for their implementation, this also encompasses deciding to what extent internal changes are necessary. Senior managers have to weigh the interests of the organization and its employees with appropriate adaptation to the new institutional environment to find a balance found appropriate by the affected employees (Habermas, 1973, p.105), and consequently are faced with the choice to either change the internal makeup as minimally as possible, or to implement more radical changes (Laughlin, 1991; Capano, 2003; Hernes, 2005). Public managers tasked with the implementation of successive reforms are therefore confronted with multiple legitimacy crises, both internal and external, which will lead to cognitive perceptions of threat on part of the managers. We thus expect that managers will operate in line with the predictions made by Staw, Sandelands \& Dutton (1981), and will attempt to improve internal coordination by focusing on the proliferation and improvement of control mechanisms and uniform work-methods, as well as draw decision-making power towards themselves to make the urgent decisions they perceive as necessary to maintain legitimacy.

On the individual level, the threat-rigidity effect predicts that employees will have to cope with stress and anxiety flowing from the threatening situation, causing them to fall back on established work patterns and avoid deviant behavior (Staw, Sandelands \& Dutton, 1981). This argument finds support in both psychological and management literature on the effects of 
reforms. The continuous surge of structural changes imposed on the organization has been observed to sever social ties, disrupt manager-employee relationships, destroy valued elements of organizational identity and place employees in unfamiliar settings and positions (e.g. Palma, Pina e Cunha \& Lopes, 2010; Pollitt, 2007; McMurray, 2010; De Vries, 2013). In addition to these social and organizational disruptions, employees are repeatedly faced with the direct threat of changes in settings, tasks and rank and reductions in benefits (e.g. Amiot et al., 2006; Nelson \& Cooper, 1995). Their focus will therefore be on surviving the variety of reforms imposed as well as possible. In this context deviant behavior will form a risky strategy, as negative appraisals by superiors may potentially have far-reaching effects on the interests of the employee during a reshuffling of the organization. Therefore, in the context of continuous organizational upheaval, we expect that risk-averse behavior will reinforce the centralization process, aiding in the generation of a more control and command oriented culture, which emphasizes rule compliance over discretionary action.

Furthermore, some contributions expect a reduction in the threat-rigidity effect if the threatening event occurred several years ago and no new threats are expected (e.g. Amabile \& Conti, 1999). However, when structural reforms are repeatedly imposed on organizations, we expect that the threat-rigidity effects of an organization's reform history will be sustained or increased, as employees in the organization have no recuperation time between past and newly imposed structural reforms.

As the organization gradually moves towards (or maintains) a culture of hierarchical control and compliance due to the repeated structural reforms imposed on it, its subsections become less well-suited for discretionary action. It is exactly this potential for discretionary action, however, which has been shown to be vital in stimulating innovation and bottom-up change in organizations (e.g. Brown \& Eisenhardt, 1997). Helpful in this regard is the concept of the ambidextrous organization (Damanpour, 1991; Tushman \& O'Reilly III; 1996; O’Reilly 
\& Tushman, 2004, 2011), which can be conceptualized as an organization having autonomous and decentralized units through which it can simultaneously pursue both incremental and discontinuous innovation (Tushman \& O'Reilly III, 1996). In their investigation of 35 organizations that maintained viable structures to stimulate the innovation of new breakthroughs, O'Reilly III \& Tushman (2004) for instance noted that successful organizations often established an independent unit with its own structures and work-processes, subject only to senior management. The independent unit could focus on the development of new products or processes and would not be bothered by the forces valuing inertia and old work-methods in other sections of the organization. The ambidextrous organization therefore implies the existence of several cultures in the organization, one associated with existing work-processes and one that is allowed to develop independently. Moreover, O'Reilly III \& Tushman (2004, p.4) argue that senior management must be particularly sensitive to the differing needs of the various parts of the organization - they have to be 'consistently inconsistent'.

Similarly, Damanpour (1991) states that although centralized structures may be more effective in implementing changes, he also states organizations that possess low degrees of centralization and formalization are better equipped to initiate the development of innovations. Mintzberg (1983) reasons along the same lines, arguing that divisionalized and bureaucratic structures impede innovation. Conversely, dynamic organizations that emphasize the discretion of small project teams, create an adaptable organizational structure and integrate their mid-level management as peers into the project teams should be better suited to innovate (Mintzberg, 1983). He succinctly summarizes the argument for the link between decentralization and innovation as: "innovation requires entrepreneurship, and entrepreneurship does not thrive under standardized external control” (Mintzberg, 1983, p.242). Brown \& Eisenhardt (1997), studying the differences between successful and less successful private innovators, similarly find that those companies linking decentralized and lowly structured work-processes with a 
steady rhythm of new projects achieve the best results, and argue that too rigidly designed workprocesses may inhibit innovation.

Contributions on public sector innovation hint at a similar link between centralization and decentralization and the extent to which governmental organizations are equipped to initiate innovations. Various scholars have pointed out that decentralized structures that promote autonomy and support new ideas are beneficial to innovative behavior, while centralized, topdown and rigid structures impede such behavior (Borins, 2001, 2002; Voorberg, Bekkers \& Tummers, 2015; Wynen et al., 2014; Arundel, Casali \& Hollanders, 2015; De Vries, Bekkers \& Tummers, 2016). Kim \& Chang (2009), while not directly testing the effect of decentralization on innovation, do note that an organizational environment which stimulates learning and information-sharing is conducive to innovative behavior. The presence of these factors in an organization imply that central managers stimulate and allow their employees to engage in these activities (see also e.g. Borins, 2001, 2002), instead of limiting their discretion through top-down command and control structures. Osborne \& Brown (2011), moreover, emphasize the importance of mandating organizational members to take the risks involved with the innovation process and to manage these risks without stifling the available space to innovate. Thus, we may expect the centralizing and risk-averse tendencies caused by the threatrigidity effect to have similar inhibiting features for innovation in the public sector as they would have in the private sector.

Based on the above, we propose that repeated reforms may generate sustained or - in some cases - increasing levels of perceived threat in the organization (see also Pollitt, 2007; Grunberg, Moore, Greenberg, 2008; De Vries, 2013). Therefore, organizations that have experienced series of (severe) reforms in their recent histories should have greater tendencies towards centralized, rigid and risk-averse behavior. These extensive reform histories should, through the threat-rigidity effect, thus also have a greater detrimental effect on the innovative 
behavior of the organization. As the repeatedly threatened organization persistently discourages risk-taking and autonomy, a culture that inhibits innovation instead of encouraging it gradually develops. Thus, we expect that an extensive history of structural reforms, which are often inter alia intended to produce flexibility and innovation, will paradoxically result in reduced levels of innovation-oriented cultures. The remainder of this paper will be devoted to empirically testing our expectations.

\section{Data source, variables and descriptive statistics}

In order to empirically test the relationship between an organization's history of structural reforms and an organization's innovation-oriented culture, we make use of two different data sources. An indicator for the structural reforms organizations experienced throughout their lifetime is constructed with the help of the Belgian State Administration Database (BSAD) while data on innovation-oriented culture is provided by the COBRAnetwork (“Comparative Public Organization Data Base for Research and Analysis"). ${ }^{1}$

The BSAD captures for all Flemish public organizations in the period between 1980 and 2013 all changes in formal organizational structure from the founding of an organization to its termination. The BSAD uses a similar structure as the Norwegian State Administration Database (NSAD). More precisely, a predefined categorization that classifies organizational change events in three main categories is used: changes related to the founding of an organization, changes related to the survival or maintenance of an organization, and changes related to the termination of an organization. For each main category of change events there are several sub-categories, including splitting, secession, merger and absorption, as well as movement of organizations vertically and horizontally within the state apparatus and into or out

${ }^{1}$ For more information, see; http://soc.kuleuven.be/io/cost/index.html. 
of it (Rolland \& Roness, 2011, 405-407). As we are interested in the effects of reforms on the culture of existing organizations, only maintenance events are taken into account. Structural reforms leading to the creation or ending of public organizations are therefore not included in our analysis. The following maintenance events, categorized according to their expected impact on the organization, are available: ${ }^{2}$

Please include Table 1 here

The BSAD allows us to vividly capture the structural reforms in the Flemish public sector, of which many stem from an array of environmental processes, such as the succession of several reform waves, inspired by NPM and Post-NPM doctrines, fast-paced societal change and economic pressures. With regard to those structural reforms inspired by administrative doctrines, the 90's and early 2000's showed an increasing preference towards New Public Management (NPM) ideas of governing, resulting in legal form changes and shifts from public to private service provision (Moynihan, 2006; Lapsley, 2009; Capano, 2003; Hacker, 2004; Palma, Pina e Cunha \& Lopes, 2010; Manville et al., 2016). Subsequently, an additional wave of structural reforms based on the post-NPM doctrine of reintegrating independent organizations and creating a joint-up government sought to combat the increasing fragmentation of the Flemish public sector (Christensen \& Lægreid, 2011; Bumgarner \& Newswander, 2012; Christensen, 2012).

Beyond these policy trends, ongoing societal and economic processes seem to be an important factor causing the imposition of structural reforms. A prominent recent example is the 2008 financial crisis and the subsequent period of austerity in European governments,

\footnotetext{
${ }^{2}$ The complete list of structural events (starting, maintenance and ending events) included in the BSAD, as well as an explanation on the categorization (major, moderate and minor) as well as an example reform trajectory can be consulted in the appendix.
} 
providing a budgetary impetus for the Flemish government to reduce the size of its government through structural reform (Vis, Van Kersbergen \& Hylands, 2011). Moreover, the ongoing devolution of powers from the federal Belgian government to the regional government has repeatedly generated structural reforms in order to accommodate newly transferred tasks and units. While these processes are the root cause for a large quantity of reforms in the Flemish public sector, a sizeable amount of ad hoc and sui generis structural reforms are also imposed on public organizations. These are not directly traceable to any of the aforementioned government-wide reforms, but are the consequence of policy sector-specific policy changes, media storms or specific incidents linked to individual organizations.

To illustrate how these environmental factors bring about structural reform in practice, the appendix includes the structural reform history of the Flemish Service for Job Mediation and Vocational Training ('Vlaamse Dienst voor Arbeidsbemiddeling en Beroepsopleiding' VDAB), one of the 45 organizations in our sample. This organization has encountered several of the aforementioned processes during its lifetime, including its creation through the devolution of powers to the regional level, the 2003-2006 NPM-inspired Better Administrative Policy reform, the privatization of some of its services and several ad hoc and sui generis structural reforms due to e.g. sector-specific changes in labour market policies.

As Flanders is an autonomous region in the federalized system of Belgium, the Flemish government enjoys substantial policymaking and policy-implementing autonomy in most sectors. A particular element of Belgian federalism is that federal laws have the same legal standing as decrees issues by the regional governments, implying that federal governments and regional governments have equal legislative and executive powers. This feature implies that the Flemish government for its own competences is to be perceived as a full-fledged government, making its public sector comparable to that of Western European states. The combined presence of substantial environmental volatility in the Flemish public sector and the region's far-reaching 
autonomy make it a suitable setting for our investigation into the effects of reform histories on innovation-oriented cultures.

Data on organizational culture comes from the COBRA-network which developed a common questionnaire in order to survey senior managers of public organizations in particular, (semi)-autonomous agencies located directly beneath ministries and ministers (see Wynen and Verhoest 2015). The top-level management (the Chief Executive Officers (CEO) level) of these organizations was asked to fill in a web-based questionnaire containing several types of questions (i.e. perceptions of autonomy and control, innovative behaviour, management and organizational culture). Although the COBRA data originally included 15 different countries, we only use the Flemish data since these can be combined with the BSAD. The response rate for the Flemish survey was $70 \%$. Missing data on the outcome, explanatory, and/or control variables, leaves us with a sample size of 45 Flemish public organizations. These organizations proved to be representative for the total population, with a broad distribution across organizational types, primary tasks and policy fields. ${ }^{3}$ Purely private-law based entities in the hands of the Flemish government were excluded from our selection, as the mechanism underlying reform stress in the public sector may not be generalizable to such hybrid organizations.

\subsection{Measuring innovation-oriented culture}

A measurement instrument for organizational culture as developed and tested by Tepeci (2001) was used in the COBRA survey (see also Lægreid et al. 2011). Following Tepeci's (2001) clustering of culture-items, the following set of items is used to construct the dependent

\footnotetext{
${ }^{3}$ The representativeness of the data was tested using Chi-square goodness of fit tests. The number of agencies per type in the sample was compared with the number of agencies per type in the population.
} 
variable on an innovation-oriented culture (see also Lægreid et al. 2011; Wynen and Verhoest. 2014; Wynen and Verhoest 2015):

- Innovation,

- Risk taking,

- Willingness to experiment, \&

- Creativity.

Each organization was asked to indicate on a scale of 0-6 how distinctive each of these items was for their organization as a whole. These scores have been aggregated and the sum has been divided by 24 , resulting in a value between 0 and 1 . This index has been found to be reliable (Cronbach's Alpha is 0.8425). This was also confirmed by an explanatory factor analysis $^{4}$, whereby all four items load on the same factor.

As discussed by Wynen \& Verhoest (2014), there is a high likelihood that this kind of measurement of culture is biased. Organizations may report to have an innovation-oriented culture, but this doesn't mean that they also exhibit innovative behavior. Hence we will conduct a similar robustness check as the one applied by Wynen \& Verhoest (2014). We will correct the original index with an index capturing the presence of 'new' and 'innovative' management techniques. This index is constructed based on the following items:

- Use of quality standards for production and/or services;

- Use of quality management systems such as; ISO, CAF, EFQM, etc.;

- Use of customer/user surveys; use of service points for users;

- Use of customer/user panels.

For each of these management techniques the agency CEO was asked to which degree these were implemented and used in their organization (scale from 0-4). These items were aggregated and divided by 16 , leading to a value between 0 and 1 . This index was found to be

\footnotetext{
${ }^{4}$ A polychoric correlation matrix was employed in order to take the categorical nature of the items into account.
} 
reliable (Cronbach's Alpha of 0.79). Moreover, all items load on the same factor when running an explanatory factor analysis ${ }^{5}$.

A 'corrected' index was created by comparing the original index with the index on the use of these innovative management techniques. In case of a divergence between the two indexes, penalties were given. This was only done in one direction; if organizations reported to have a higher score for innovation-oriented culture than the actual score on the use of innovative management techniques. Such a robustness check thus corrects for an overestimation of the value for innovation-oriented culture. A complete list of penalties per difference between the indexes is provided in Table 2.

Please include Table 2 here

\subsection{An organization's history of structural reforms}

Based on information from the $\mathrm{BSAD}$, it was possible to construct for each organization an indicator for its history of structural reforms. This history was reconstructed starting from the founding date of each organization until the survey year of the COBRA data (2013). This is calculated in two steps. First, we calculate for each organization a value for organizational history based on the following formula;

$$
\sum\left(\frac{\text { Strength of an event }}{(2013-\text { Year of reform event })}\right)^{2}
$$

Here year of reform event refers to the date when the event took place and 2013 refers to the survey year of the COBRA data. Organizational history is taken into account until that

\footnotetext{
${ }^{5}$ Again using a polychoric correlation matrix to take the categorical nature of the items into account.
} 
year. The impact of each reform event dependents on the date when it occurred. The further away in time, the lower its impact factor. It is important to note that we included a squared term in order to account for the fact that the effect of reform is expected to decrease in a nonlinear way. Strength of an event is a subjective measure that corresponds to the three levels of reforms distinguished earlier (see Table 1, and appendix for a more thorough discussion). More accurately: in case of a major reform the numerator has been set to 3 , to 2 if the event is expected to have a moderate effect on the organization and the numerator is equal to 1 if the effect of the event is expected to be minor. Each reform the organization encountered is as such given an impact. These impact factors have been aggregated per organization. This in turn led, for each organization, to a value for its history of reforms.

It is however, likely that organizations compare their own history of reforms with that of other organizations within the same government. In a second step, an organization's history of reforms is therefore related to the average history which is calculated across all organizations.

$$
\text { Organizational history of reforms }=\frac{(1)}{\text { mean }(1)}
$$

A significant negative impact for this indicator (2) would imply that large amounts of structural reforms imposed on an organization will be detrimental to the degree to which it possesses an innovation-oriented culture.

\subsection{Control variables}

Furthermore, we control for some other factors which are based on previous studies, believed to influence organizational culture (e.g. Verhoest et al. 2010, Lægreid et al. 2011, Wynen et al. 2014). This reflects the idea that innovation-oriented culture may be determined in part by differences in the characteristics and design of public organizations, such as their 
tasks and size (Borins, 1998; Damanpour, 1991; Lægreid et al. 2011). Our dataset allows us to control specifically for the following factors:

1) A dummy Type is included in order to examine the effects of agency type. Type is coded 0 if the organization is a department, and 1 if the organization is one of the various types of arms-length and independent agencies in the Flemish system. According to literature (Bouckaert \& Van Dooren, 2003; Bach and Jann, 2010) organizations closer to government are less in direct contact with citizens and are more politicized, which is typically seen as hampering an innovation-oriented culture.

2) Task related factors are also taken into account by the inclusion of a dummy (Services). The dummy equals 1 if the agency's primary task includes general public services or business and industrial services. It equals 0 for primary tasks related to regulation, exercising public authority and policy formulation. Agencies having service delivery as primary task have been found to have a greater focus on customers since they interact most with citizens and private organizations as customers (Borins 1998; Lægreid et al. 2011). This in turn is expected to have a positive effect on an innovation-oriented culture.

3) Size (Size (FTE)) measured in FTE is included as a continuous variable. Following Hull \& Hage (1982), Borins (2001) and Damanpour (1989, 1991) size can have an effect on organizational culture.

4) Age (Age) measured as 2013- founding date is included as a continuous variable. The development of a distinct culture and tradition within an organization takes some time (Lægreid et al. 2011). As such age can be linked to organizational culture (Krause 2003).

Because the distributions of Size and Age are highly skewed, we use the logarithms, that is; $\ln ($ Size $)$ and $\ln ($ Age $)$ in our models. 
Table 3 shows summary statistics for the main variables, while in Table 4 the correlation matrix is presented. Not surprisingly there appears to be a strong correlation between task and type of public organization. Consequently, we also test for multicollinearity using the variance inflation factor. The mean VIF equals 1.29 whereby, as expected, the highest VIFs exist for Task (1.50) and Type (1.40). These values indicate that no collinearity exists between the variables.

Please include Table 4 here

\section{Analysis and results}

Standard micro-econometric techniques are employed for the multivariate analysis. More precisely, standard Ordinary Least Squares (OLS) is utilized. Admittedly, Tobit models are the preferred estimations, as they account for the fact that our dependent is bounded between

0 and 1 . However, these estimations rely on the restrictive assumption of normality and are sensitive to small sample bias (Long, 1997). OLS does not take into account that our dependent is bounded at 1 , but has the advantage of not relying on the normality assumption and being less sensitive to small sample bias. We therefore opted to only present the OLS results. However, the Tobit results led to similar results (same sign and significance levels) and are available upon request from the authors.

The OLS results are presented in Table 5. In the first column, the effect of organizational history, taking the number of reforms, the strength and time effect of a reform event, and history of other organizations into account, is examined on the original index of an innovation-oriented culture. While in the last column organizational history is tested on the 'corrected' index on an 
innovation-oriented culture (Robustness Check). Both models have been tested for heteroscedasticity, revealing no significant methodological issues.

\section{Please include Table 5}

When examining the results for the original index of an innovation-oriented culture, we notice that the effect of reform history is negative and significant. Consequently, organizations with a more turbulent history of reforms are less likely to develop an innovation-oriented culture. This finding seems to support our proposition that larger and more severe histories of reforms will inhibit innovation-oriented cultures, and will instead cause the exact opposite. As was noted in section 2, we consider the most likely explanation for this observation that too many reforms imposed in a too short a time span lead to more centralized structures within the organization, which in turn hampers the innovation-oriented culture within these organizations. As a robustness check we also tested different operationalisations of organizational history (one which only accounts for the number of events an organization encountered and one which takes the number and strength of events into account). However, the results did not differ significantly and thus proved that these are robust.

None of the other explanatory variables (Task, Age, Size and Type) have a significant effect on innovation-oriented culture.

Yet as discussed, the original index of an innovation-oriented culture is likely to be biased. What organizations say they do, does not necessarily reflect in their behaviour. Hence we have constructed a more robust measure whereby we compare the original index with an index on the presence of innovative management techniques within the organization. The regression results on this 'corrected' index of an innovation-oriented culture is presented in the last column of Table 5. Results however stay the same; too many reforms lead to a lower degree 
of an innovation-oriented culture. In short, it does appear that our initial results on the original index of an innovation-oriented culture are robust.

\section{Discussion}

In this paper we have proposed that turbulent structural reform histories may adversely affect the degree of innovation-oriented culture in public organizations. We have argued that the upheaval caused by the imposition of frequent and severe structural reforms on public organizations may result in organizations reflexively centralizing to cope with the threatening situation (Staw, Sandelands \& Dutton, 1981; Amabile \& Conti, 1999; Daly et al., 2011). In turn, such a centralized and rigid structure was argued to be unconducive to an innovationoriented culture of an organization, as uniformity, control and coordination are emphasized above autonomy and discretionary action. However, room for discretionary action, support for the activities and ideas of employees that directly execute the organization's tasks and a tolerance for risk are consistently mentioned as important factors in fostering an organization's innovativeness (Damanpour, 1991; Tushman \& O'Reilly III, 1996; Borins, 2001, 2002; Voorberg, Bekkers \& Tummers, 2015; Arundel, Casali \& Hollanders, 2015; De Vries, Bekkers \& Tummers, 2016), and it is exactly these factors which are diminished by the threat-rigidity effect.

The results presented in the previous section provide support for these arguments. Utilizing data on the structural reforms imposed on Flemish public organizations as well as selfreport surveys on innovative culture, two regression models were developed. These models indicate that structural reform histories significantly impact the degree to which organizations possess an innovation-oriented culture. Organizations that had recently undergone trajectories of severe and frequent structural reforms were shown to possess a relatively lower score on our items of innovative culture (corrected by scores for usage of innovative management 
techniques). This effect remained significant after controlling for other factors which have been suggested as antedecents to innovation-oriented organizational culture, specifically task, type, size and age variables (Hull \& Hage, 1982; Borins 1998; Damanpour, 1989; Damanpour, 1991; Krause, 2003; Lægreid et al. 2011), which suggests that our results are robust.

Our findings corroborate the arguments made by the burgeoning literature on the sideeffects of extensive and repeated reform programs following doctrines such as NPM and postNPM (Pollitt, 2007; De Vries, 2013; McMurray, 2010). It seems that more turbulent structural reform histories are indeed capable of generating a state of organizational upheaval, in which successive reforms result in potentially unintended consequences for public organizations. Furthermore, the results presented here also seem to provide indirect support for theories on the threat-rigidity effect (Staw, Sandelands \& Dutton, 1981) and the crisis-centralization thesis (Dutton, 1986; Olson \& Sexton, 2009). While centralization and rigidity were not directly tested with our data, earlier work positing these variables as potentially being caused by threats such as structural reforms and potentially resulting in less innovation-oriented organizational cultures make them likely candidates for the causal mechanism underlying the relationships found in the course of our study. Our examination of the organizational-level consequences of the stress incurred by structural reforms across a variety of organizations thus lends further support to already existing theories from organizational psychology and public reform literature, which up until now have largely remained limited to studying one or several organizations (e.g. Dutton, 1986; Olson \& Sexton, 2009; Grunberg, Moore, Greenberg, 2008; McMurray, 2010, but see De Vries, 2013).

Simultaneously, the contribution adds novel insight into the factors that contribute to the development of innovation-oriented cultures - or the lack thereof - in the context of the public sector, as to our knowledge this article is the first to measure the impact of multiple reforms of varying severity (e.g. Damanpour \& Schneider, 2009; Damanpour, 1991; De Vries, 
Bekkers \& Tummers, 2014). According to the results, organizations attempting to stimulate an innovation-oriented culture should avoid imposing reforms too frequently, as this could be counterproductive to their intentions. Instead, organizations should aim for a balance where necessary changes are implemented but enough time is given for the organization to recuperate from the (structural) reform before a new set of changes is introduced.

At this point it is also important to note that our results do not necessarily imply that every type of organizational change is detrimental to an organization, and other researchers have for instance found that organizations capable of steady, internally developed changes on the project level are better innovators (Brown \& Eisenhardt, 1997). Similarly, it is worth reiterating that a single structural reform in itself might have beneficial effects (see e.g. Dan and Pollitt 2015). Our argument does not undermine the validity of these viewpoints as it looks at a specific form of organizational change. We posit that when an organization undergoes multiple and externally dictated structural reforms during its lifetime, these reform events will repeatedly generate stress for employees. In turn, the stress accumulated from a fast-paced sequence of severe structural reforms results in detrimental side-effects on innovation-oriented culture.

Finally, although this paper is only a first exploration of the effects that successive reforms may have on organizational culture in the public sector, our results nevertheless also hold some important practical implications. In particular, the paper suggests that unintended side-effects and an organization's history should be important considerations for policy-makers and politicians to take into account when deciding upon the implementation of a reform.

Our analysis was limited by several factors, which warrant some caution when interpreting our results. While we possessed a representative sample of organizations in the Flemish public sector, the sample size was unfortunately relatively low. Furthermore, the crosssectional data on our dependent variables imply that some uncertainty still exists on the causal 
direction of the relationships found. It is not entirely ruled out that organizations that perform poorly on innovation are reformed more often, or that a dual causation exists whereby both a low degree innovation-oriented culture and a high amount of reforms explain one another. Nevertheless, as many reforms in our sample are attributable to factors other than organizational performance, including politicization of the organization and the aim of governments to implement new management ideas, it is relatively safe to assume that our interpretation of the causal direction is correct. Finally, while the research seems to indirectly support the presence of a centralizing reflex in heavily reformed organizations, the data utilized here only allows us to presuppose the existence of this reflex through theoretical arguments.

\section{Conclusion}

In this article we examined the impact of histories of structural reforms on the innovation-oriented cultures of public organizations in the Belgian region of Flanders. The results of our analysis provide support for the argument that frequent and severe reforms may have significant and detrimental side-effects on an organization, even after controlling for other factors such as age, task, size and type. The article adds valuable quantitative findings to the literature on organizational-level consequences of the stress incurred by structural reforms, as studies conducted up until now have largely remained confined to studying only one or several organizations (e.g. Dutton, 1986; Amiot et al., 2006; Grunberg, Moore, Greenberg, 2008; McMurray, 2010).

In addition to the immediate implications of the analysis for the design of future reform programs, the results suggest that reform history is a promising avenue for further inquiry. Moreover, as this contribution is explorative in nature, further research is needed to confirm and complement the analyses presented here. Research that also incorporates panel data is particularly necessary, as this will allow for the verification of the causal direction of the 
relationship found in our paper. Such a research design could also include variables on various cultural orientations, centralization and control in order to more fully test the causal mechanism proposed here. As government reforms are frequently being imposed on public organizations, such research into the detrimental, unintended and unexpected effects that these reforms can cause is more necessary than ever.

\section{References}

Amabile, T.M., Conti, R. (1999), Changes in the work environment for creativity during downsizing, Academy of Management Journal, 42:6, pp.630-640

Amiot, C.E., Terry, D.J., Jimmieson, N.L., Callan, V.J. (2006), A longitudinal investigation of coping processes during a merger: implications for job satisfaction and organizational identification, Journal of Management, 32:4, pp.552-574

Arundel, , A., Casali, L., Hollanders, H. (2015), How European public sector agencies innovate: The use of bottom-up, policy-dependent and knowledge-scanning innovation methods, Research Policy, 44:7, pp.1271-1282

Bach, T., Jann, W. (2010), Animals in the administrative zoo: Organizational change and agency autonomy in Germany, International Review of Administrative Sciences, 76:3, pp. $443-468$

Bouckaert, G., Van Dooren, W. (2003), Performance measurement and management in public sector organizations, in: Boivard, T., Löffler, E. (eds.), Public Management and governance, London: Routledge

Borins, S. (1998), Innovating with integrity: How local heroes are transforming American government, Washington, DC: Georgetown University Press 
Borins, S. (2001), Encouraging innovation in the public sector, Journal of Intellectual Capital, 2:3, pp.310-319

Borins, S. (2002), Leadership and innovation in the public sector, Leadership \& Organizational Development Journal, 23:8, pp.467-476

Boyne, G.A., Meier, K.J. (2009), Environmental turbulence, organizational stability and public service performance, Administration and Society, 40:8, pp.799-824

Bumgarner, J., Newswander, C.B. (2012), Governing alone and with partners: presidential governance in a post-NPM environment, Administration \& Society, 44:5, pp.546-570

Brown, S.L., Eisenhardt, K.M. (1997), The art of continuous change: linking complexity theory and time-paced evolution in relentlessly shifting organizations, Administrative Science Quarterly, 42:1, pp.1-34

Capano, G. (2003), Administrative traditions and policy change: when policy paradigms matter. The case of Italian administrative reform during the 1990s, Public Administration, 81:4, pp.781-801

Christensen, T., Lægreid, P. (2011), Democracy and administrative policy: contrasting elements of New Public Management (NPM) and post-NPM, European Political Science Review, 3:1, pp.125-146

Christensen, T. (2012), Post-NPM and changing public governance, Meiji Journal of Political Science and Economics, 1, pp.1-11

Damanpour, F., Szabat, K.A., Evan, W.M. (1989), The relationship between types of innovation and organizational performance, Journal of Management Studies, 26:6, pp.587-601

Damanpour, F., Gopalakrishnan, S. (1998), Theories of organizational structure and innovation adoption: the role of environmental change, Journal of Engineering and Technology Management, 15:1, pp.1-24 
Damanpour, F. (1991), Organizational innovation: a meta-analysis of effects of determinants and moderators, Academy of Management Journal, 34:3, pp.555-590

Damanpour, F., Schneider, M. (2009), Characteristics of innovation and innovation adoption in public organizations: assessing the role of managers, Journal of Public Administration Research and Theory, 19:3, pp.495-522

Dan, S., Politt, C. (2015), NPM can work: an optimistic review of the impact of New Public Management reforms in central and eastern Europe, Public Management Review, 17:9, pp.1305-1332

Daly, A.J., Der-Martirosian, C., Ong-Dean, C., Park, V., Wishard-Guerra, A. (2011), Leading under sanction: Principals' perceptions of threat rigidity, efficacy and leadership in underperforming schools, Leadership and Policy in Schools, 10:2, pp.171-206

DiMaggio, P.J., Powell, W.W. (1983), The iron cage revisited: institutional isomorphism and collective rationality in organizational fields, American Sociological Review, 48:2, pp. $147-160$

Dorabjee, S., Lumley, C.E., Cartwright, S. (1998), Culture, innovation and successful development of new medicines - an exploratory study of the pharmaceutical industry, Leadership \& Organization Development Journal, 19:4, pp.199-210

Dutton, J.E. (1986), The processing of crisis and non-crisis strategic issues, Journal of Management Studies, 23:5, pp.501-517

Frambach, R.T., Schillewaert, N. (2002), Organizational innovation adoption: a multi-level framework of determinants and opportunities for future research, Journal of Business Research, 55:2, pp.163-176

Grunberg, L., Moore, S., Greenberg, E.S. (2008), The changing workplace and its effects: a longitudinal examination of employee responses at a large company, The Journal of Applied Behavioral Science, 44:2, pp.215-236 
Habermas, J. (1973), Legitimation crisis, Boston: Beacon Press

Hacker, J.S. (2004), Dismantling the health care state? Political Institutions, public policies and the comparative politics of health reform, British Journal of Political Science, 34:4, pp.693-724

Hernes, T. (2005), Four ideal-type organizational responses to New Public Management reforms and some consequences, International Review of Administrative Sciences, $71: 1$, pp.5-17

Hogan, S.J., Coote, L.V. (2014), Organizational culture, innovation, and performance: a test of Schein's model, Journal of Business Research, 67:8, pp.1609-1621

Hull, F.M., Hage, J. (1982), Organizing for innovation: Beyond the Burns and Stalker's organic type, Sociology, 16:4, pp.564-577

Kim, S.E., Chang, G.W. (2009), An empirical analysis of innovativeness in government: findings and implications, International Review of Administrative Sciences, 75:2, pp. 293-310

Kontoghiorghes, C., Awbrey, S.M., Feurig, P.L. (2005), Examining the relationship between learning organization characteristics and change adaptation, innovation, and organizational performance, Human Resource Development Quarterly, 16:2, pp.185212

Krause, G.A. (2003), Agency risk propensities involving the demand for bureaucratic discretion, in: Krause, G.A., Meier, K.J. (eds.), Politics, policy and organizations: Frontiers in the scientific study of bureaucracy, Ann Arbord, MI: University of Michigan University Press

Lægreid, P., Rolland, V.W., Roness, P.G., Ågotnes, J. (2010), The structural anatomy of the Norwegian state: increased specialization or a pendulum shift?, in: Lægreid, P., 
Verhoest, K. (eds.), Governance of Public Sector Organizations, London: Palgrave Macmillan, pp.21-43

Lægreid, P., Roness, P.G., Verhoest, K. (2011), Explaining the innovative culture and activities of state agencies, Organization Studies, 32:10, pp.1321-1347

Lapsley, I. (2009), New Public Management: the cruellest invention of the human spirit? ABACUS, 45:1, doi: 10.1111/j.1467-6281.2009.00275.x

Laughlin, R.C. (1991), Environmental disturbances and organizational transitions and transformations: some alternative models, Organization Studies, 12:2, pp.209-232

Long J., 1997. Regression Models for Categorical and Limited Dependent Variables. Advanced Quantitative Tools in the Social Sciences 7. Sage Publications: Thousand Oaks, CA.

MacCarthaigh, M., Roness, P. (2012), Analyzing longitudinal continuity and change in public sector organizations, International Journal of Public Administration, 35:12, pp.773782

Manville, G., Greatbanks, R., Wainwright, T., \& Broad, M. (2016). Visual performance management in housing associations: a crisis of legitimation or the shape of things to come?, Public Money \& Management, 36:2, pp.105-112

Marks, M.L., Mirvis, P.H. (1997), Revisiting the merger syndrome: dealing with stress, Mergers and Acquisitions, 31:6, pp.21-27

Martins, E.C., Treblanche, F. (2003), Building organizational culture that stimulates creativity and innovation, European Journal of Innovation Management, 6:1, pp.64-74

McMurray, R. (2010), Our reforms, our partnerships, same problems: the chronic case of the English NHS, Public Money and Management, 27:1, pp.77-82

Mintzberg, H. (1983), Structure in fives: designing effective organizations, Englewood Cliffs, NJ: Prentice Hall Inc. 
Mishra, A.K. (1996), Organizational responses to crisis: the centrality of trust, in: Kramer, R.M., Tyler, T., Trust in Organizations, Newbury Park, CA: Sage, pp.261-287

Moore, S., Grunberg, L., Greenberg, E.S. (2004), Repeated downsizing contact: the effects of similar and dissimilar layoff experiences on work and well-being outcomes, Journal of Occupational Health Psychology, 9:3, pp.247-257

Moynihan, D.P. (2006), Ambiguity in policy lessons: the agencification experience, Public Administration, 84:4, pp.1029-1050

Nelson, A., Cooper, C.L. (1995), Uncertainty amidst change: the impact of privatization on employee job satisfaction and well-being, Journal of Occupational and Organizational Psychology, 68, pp.57-71

Nyhan, R.C. (2000), Changing the paradigm: trust and its role in public sector organizations, American Review of Public Administration, 30:1, pp.87-109

Olson, B., Sexton, D. (2009), Threat rigidity, school reform, and how teachers view their work inside current education policy contexts, American Educational Research Journal, 46:9, pp.9-44

Osborne, S. P. (1998). The innovative capacity of voluntary organisations: managerial challenges for local government. Local Government Studies, 24:1, pp.19-40.

Osborne, S.P., Brown, L. (2011), Innovation, public policy and public services delivery in the UK: the word that would be king?, Public Administration, 89:4, pp.1335-1350

O’Reilly III, C.A., Tushman, M.L. (2004, April), The ambidextrous organization, The Harvard Business Review, pp.74-81

O’Reilly III, C.A., Tushman, M.L. (2011), Organizational ambidexterity in action: how managers explore and exploit, California Management Review, 53:4, pp.5-22

Palma, P.J., Pina e Cunha, M., Lopes, M.P. (2010), The best of two worlds, Public Management Review, 12:5, pp.725-746 
Parry, K., Proctor-Thomson, S. (2003), Leadership, culture and performance: the case the of the New Zealand public sector, Journal of Change Management, 3:4, pp.376-399

Pennings, J.M. (1987), Structural contingency theory: a multivariate test, Organization Studies, 8:3, pp.223-240

Pollitt, C. (2007), New Labour's re-disorganization: hyper-modernism and the costs of reform — a cautionary tale, Public Management Review, 9:4, pp. 529-543.

Pollitt, C., Dan, S. (2011), The impacts of the New Public Management in Europe: a metaanalysis (COCOPS Work Package 1 - Deliverable 1.1)

Quirke, B. (1995) Communicating Change, London: McGraw-Hill.

Rolland, V.W., Roness, P.G. (2011), Mapping organizational change in the state: challenges and classifications, International Journal of Public Administration, 34:6, pp.399-409

Roness, P.G., Verhoest, K., Rubecksen, K., MacCarthaigh, M. (2008), Autonomy and regulation of state agencies: reinforcement, indifference or compensation, Public Organization Review, 8:2, pp.155-174

Schein, E. H. (2000), Organizational Culture and Leadership, San Francisco, CA: JosseyBass

Seo, M., Hill, N.S. (2005), Understanding the human side of merger and acquisition: an integrative framework, The Journal of Applied Behavioral Science, 41:4, pp.422-443

Staw, B.M., Sandelands, L.E., Dutton, J.E. (1981), Threat rigidity effects in organizational: a multilevel analysis, Administrative Science Review Quarterly, 26:4, pp.501-524

Tepeci, M. (2001), The effect of personal values, organizational cultures, and personorganization fit on individual outcomes in the restaurant industry, University Park, PA: School of Hotel, Restaurant and Recreation Management, Pennsylvania State University, Doctoral Dissertation 
Tushman, M.L., O’Reilly III, C.A. (1996), Ambidextrous organizations: managing evolutionary and revolutionary change, California Management Review, 38:4, pp.8-30

Valle, M. (1999), Crisis, culture and charisma: the new leader's work in public organizations, Public Personnel Management, 28:2, pp.245-257

Verschuere, B., Barbieri, D. (2009), Investigating the 'NPM-ness' of agencies in Italy and Flanders, Public Management Review, 11:3, pp.346-373

Voorberg, W.H., Bekkers, V.J.J.M., Tummers, L.G. (2015), A systematic review of cocreation and co-production: embarking on the social innovation journey, Public Management Review, 17:9, pp.1333-1357

de Vries, M.S. (2013), Reform fatigue: the effects of reorganizations on public sector employees, retrieved on 27-01-2016 from: http://www.nispa.org/files/conferences/speeches/201304191553120.nispa\%202013\%0 De\%20Vries\%20Reform_fatigue.pdf

de Vries, H.A., Bekkers, V.J.J.M., Tummers, L.G. (2016), Innovation in the public sector: a systematic review and future research agenda, Public Administration, 94:1, pp.146166

Vis, B., van Kersbergen, K., Hylands, T. (2011), To what extent did the financial crisis intensify the pressure to reform the welfare state?, Social Policy \& Administration, 45:4, pp.338-353

Walker, R.M., Boyne, G.A. (2006), Public management reform and organizational performance: an empirical assessment of the U.K. Labour Government's public service improvement strategy, Journal of Policy Analysis and Management, 25:2, pp.371-393 
Wynen, J., Verhoest, K., van Thiel, S., Ongaro, E. (2014), Innovation-oriented culture in the public sector: do managerial autonomy and result control lead to innovation? Public Management Review, 16:1, pp.45-66

Wynen, J., Verhoest, K., (2015), Do NPM-type reforms lead to a cultural revolution within public sector organizations?, Public Management Review, 17:3., pp.356-379 


\section{Tables \& Figures}

Table 1 Available maintenance events in the BSAD, categorized according to their expected impact on the organization

\begin{tabular}{l|l|l}
\hline \hline \multicolumn{1}{c|}{ Major impact } & \multicolumn{1}{c|}{ Moderate impact } & \multicolumn{1}{c}{ Minor impact } \\
\hline $\begin{array}{l}\text { Restructuring the organization } \\
\text { by absorption of (parts or tasks } \\
\text { from) another organization }\end{array}$ & $\begin{array}{l}\text { Restructuring the organization } \\
\text { by changing its legal status }\end{array}$ & $\begin{array}{l}\text { Restructuring the organization } \\
\text { by shifting organizations to } \\
\text { another ministerial portfolio } \\
\text { (sub-ordinance to another } \\
\text { ministry) }\end{array}$ \\
$\begin{array}{l}\text { Restructuring the organization } \\
\text { by secession of parts or tasks of } \\
\begin{array}{l}\text { the organization (which are } \\
\text { shifted to other organizations) }\end{array}\end{array}$ & $\begin{array}{l}\text { Restructuring the organization } \\
\text { by the attribution of new tasks, } \\
\text { not existing before in the public } \\
\text { sector }\end{array}$ & Change of name \\
\hline
\end{tabular}


Table 2 Construction robustness check innovation-oriented culture

\begin{tabular}{cc|c}
\hline \hline $\begin{array}{c}\text { Difference between the index on an } \\
\text { innovation-oriented culture and the } \\
\text { index on the use of innovative } \\
\text { management techniques equals: }\end{array}$ & $\begin{array}{l}\text { Penalty (the } \\
\text { initial index of } \\
\text { an innovation- } \\
\text { oriented culture } \\
\text { is reduced by:) }\end{array}$ \\
\hline 0.1 & 0.2 & 0.1 \\
0.2 & 0.3 & 0.2 \\
0.3 & 0.4 & 0.3 \\
0.4 & 0.5 & 0.4 \\
0.5 & 0.6 & 0.5 \\
0.6 & 0.7 & 0.6 \\
0.7 & 0.8 & 0.7 \\
0.8 & 0.9 & 0.8 \\
0.9 & 1 & 0.9 \\
\hline
\end{tabular}


Table 3 Descriptive statistics ( $N=45)$

\begin{tabular}{|c|c|c|c|c|c|}
\hline Variable & Description & Mean & SD & Min & $\operatorname{Max}$ \\
\hline Organizational history of reforms & $\begin{array}{l}\text { This variable reflects the number, severeness and sequence of reforms an organization } \\
\text { encountered and simultaneously takes the history of other organizations into account. }\end{array}$ & 1.135581 & 2.850915 & 0 & 16.26975 \\
\hline Innovation-oriented culture (origial) & $\begin{array}{l}\text { Index based on the following items: innovation, risk taking, willingness to experiment and } \\
\text { creativity }\end{array}$ & .6714286 & .1352693 & .4285714 & .9285714 \\
\hline $\begin{array}{l}\text { Innovation-oriented culture (robustness } \\
\text { check) }\end{array}$ & $\begin{array}{l}\text { The original index which is corrected for the use of the following innovative management } \\
\text { techniques: use of quality standards for production and/or services; use of quality management } \\
\text { systems such as; ISO, CAF, EFQM,...; use of customer/user surveys; use of service points for } \\
\text { users; use of customer/user panels. }\end{array}$ & .6135556 & .1419852 & .38 & .89 \\
\hline Age $(\log )$ & 2013 - birthdate $(\log )$ & 2.438964 & .6916568 & .6931472 & 3.496508 \\
\hline Type & Type $(0=$ Department $/ 1=$ otherwise $)$ & .8222222 & .3866458 & 0 & 1 \\
\hline Size $(\log )$ & Size (number of FTE) (log) & 5.451725 & 1.107408 & 2.902047 & 8.289564 \\
\hline Task & Service delivery ( $0=$ primary task other than service delivery $/ 1=$ service delivery as primary task) & .5111111 & .505525 & 0 & 1 \\
\hline
\end{tabular}


Table 4 Correlation matrix

\begin{tabular}{lc|cccccc}
\hline \hline \multicolumn{1}{c|}{ Variables } & & $(1)$ & $(2)$ & $(3)$ & $(4)$ & $(5)$ & $(6)$ \\
\hline Organizational history of reforms & $(1)$ & 1 & & & & & \\
Innovation-oriented culture (original index) & $(2)$ & $-0.300^{* *}$ & 1 & & & & \\
Age & $(3)$ & -0.0905 & 0.171 & 1 & & & \\
Type & $(4)$ & -0.0707 & 0.00621 & $0.356^{* *}$ & 1 & & \\
Size & $(5)$ & 0.0326 & -0.048 & 0.241 & 0.0835 & 1 & \\
Task & $(6)$ & -0.218 & 0.0309 & $0.249^{*}$ & $0.475^{* * *}$ & $0.299^{* *}$ & 1 \\
\hline
\end{tabular}

* $\mathrm{p}<0.10, * * \mathrm{p}<0.05, * * * \mathrm{p}<0.01$ 
Table 5 Regression (OLS) results for the impact of history on an innovation-oriented culture

\begin{tabular}{|c|c|c|}
\hline \multirow{2}{*}{ Variables } & \multirow[b]{2}{*}{ Original index } & \multirow[b]{2}{*}{ Robustness check } \\
\hline & & \\
\hline Organizational history of reforms & $\begin{array}{c}-0.0138^{*} \\
(0.00736)\end{array}$ & $\begin{array}{c}-0.0151 * \\
(0.0076)\end{array}$ \\
\hline Age $(\log )$ & $\begin{array}{l}0.0371 \\
(0.032)\end{array}$ & $\begin{array}{c}0.0422 \\
(0.0329)\end{array}$ \\
\hline Type & $\begin{array}{l}-0.0219 \\
(0.0628)\end{array}$ & $\begin{array}{l}-0.00194 \\
(0.0646)\end{array}$ \\
\hline Size $(\log )$ & $\begin{array}{l}-0.0086 \\
(0.0198)\end{array}$ & $\begin{array}{c}0.0145 \\
(0.0204)\end{array}$ \\
\hline Task & $\begin{array}{l}-0.00786 \\
(0.0491)\end{array}$ & $\begin{array}{l}-0.0127 \\
(0.0506)\end{array}$ \\
\hline Constant & $\begin{array}{c}0.664 * * * \\
(0.119)\end{array}$ & $\begin{array}{c}0.455^{* * * *} \\
(0.122)\end{array}$ \\
\hline Observations & 45 & 45 \\
\hline R-squared & 0.122 & 0.156 \\
\hline Log-Likelihood Full Model & 29.602 & 28.305 \\
\hline Breush Pagan test for heteroskedasticity & $\chi^{2}(1)=1.54$ & $\chi^{2}(1)=1.09$ \\
\hline Skewness and kurtosis test for normality dep. var. & $\chi^{2}(2)=2.71$ & $\chi^{2}(2)=3.69$ \\
\hline
\end{tabular}




\section{Appendix}

\section{Overview of BSAD event codes}

\section{Founding events}

101 - pure founding (organization has no predecessors)

102 - founding by secession (except from bodies from other government levels)

104 - founding by splitting (except from bodies from other government levels)

106 - founding by merger (except from bodies from other government levels)

107 - founding by transfer from national/federal level (regionalization), including immediate merger or splitting of the organization

108 - founding by transfer from lower administrative level (from local/provincial to regional/federal or from regional to federal)

111 - founding by complex reorganization (except from bodies from other government levels)

112 - entered; new relevant entity (not existing in dataset before)

114 - founding by complex splitting

116 - founding by complex merger

\section{Maintenance events}

202 - maintenance by secession (to bodies of the same governmental level or to private sector/non-profit sector)

203 - maintenance by absorption (from bodies of the same governmental level or from private sector/non-profit sector)

204 - maintenance with secession of tasks to another governmental level

205 - maintenance by absorption of tasks from another governmental level

207 - maintenance by only change of name

208 - maintenance by dropping of tasks altogether

211 - maintenance by reorganization

221 - new superior organization at the same level (horizontal movement)

222 - new form of affiliation/legal form (including moving in or out private or non-profit sector) (with or without change of name)

223 - new superior organization and new form of affiliation/legal form

224 - maintenance by the adoption of new tasks (not existing before in any other (public)

organization)

291 - no change to unit, but change of superior (diagonal movement at the same governmental level)

\section{Ending events}

303 - ending by absorption

304 - ending by splitting

306 - ending by merger

307 - ending by transfer to regional level (regionalization)

308 - ending by transfer to provincial and local administrative levels 
309 - ending by transfer to higher administrative level (from regional to federal or from lower levels to regional/federal)

310 - pure disbandings/termination

311 - ending by complex reorganization

312 - discharged; no longer relevant entity

314 - ending by complex merger

316 - ending by complex splitting

\section{Expected impact of a reform (see also Table 1)}

We propose that different types of structural reforms have different degrees of impact on an organization, based on the characteristics of these reforms. The 'level 3'- reforms all concern the integration or secession of sections, tasks and activities in the organization and are therefore considered to be particularly likely to cause a threat-rigidity effect. They directly - and sometimes detrimentally - alter the organization's internal makeup and tasks and imply major changes for the employees involved. The 'level 2'-reforms that are proposed to have a moderate effect have more diverse characteristics. A change of legal form does not necessarily entail a change in makeup or task, but it does signal a shift to other work-methods, a different relationship with the political superior, a different accountability structure, a different level of legal/financial autonomy and a revised set of administrative and/or private law competences for the organization concerned. Conversely, the internal reorganization is capable of having a relatively strong impact on the organization's makeup, but is controlled to a greater extent by internal managers and is therefore expected to be less of an external threat than the 'level 3' reforms. Finally, an adoption of new tasks may encumber the organization with heightened workload, but is normally not a threat to the position of current organization's members or the organization's legitimacy. The 'level 1' - category concerns structural reform events that should only produce relatively minor levels of threat perceptions in organizations. The first of the minor impact events is the shift to another ministerial portfolio, which implies a changing accountability relationship but otherwise does not change the organization. The second minor impact event, the change of name, only replaces the superficial symbols of an organization and 
not its core mechanics, activities, or makeup, and is therefore also expected to generate relatively low levels of threat-rigidity in the organization. 


\section{Example Reform Trajectory}

Figure 1 Schematic representation of the reform history of the Flemish Service for Employment Mediation (VDAB)

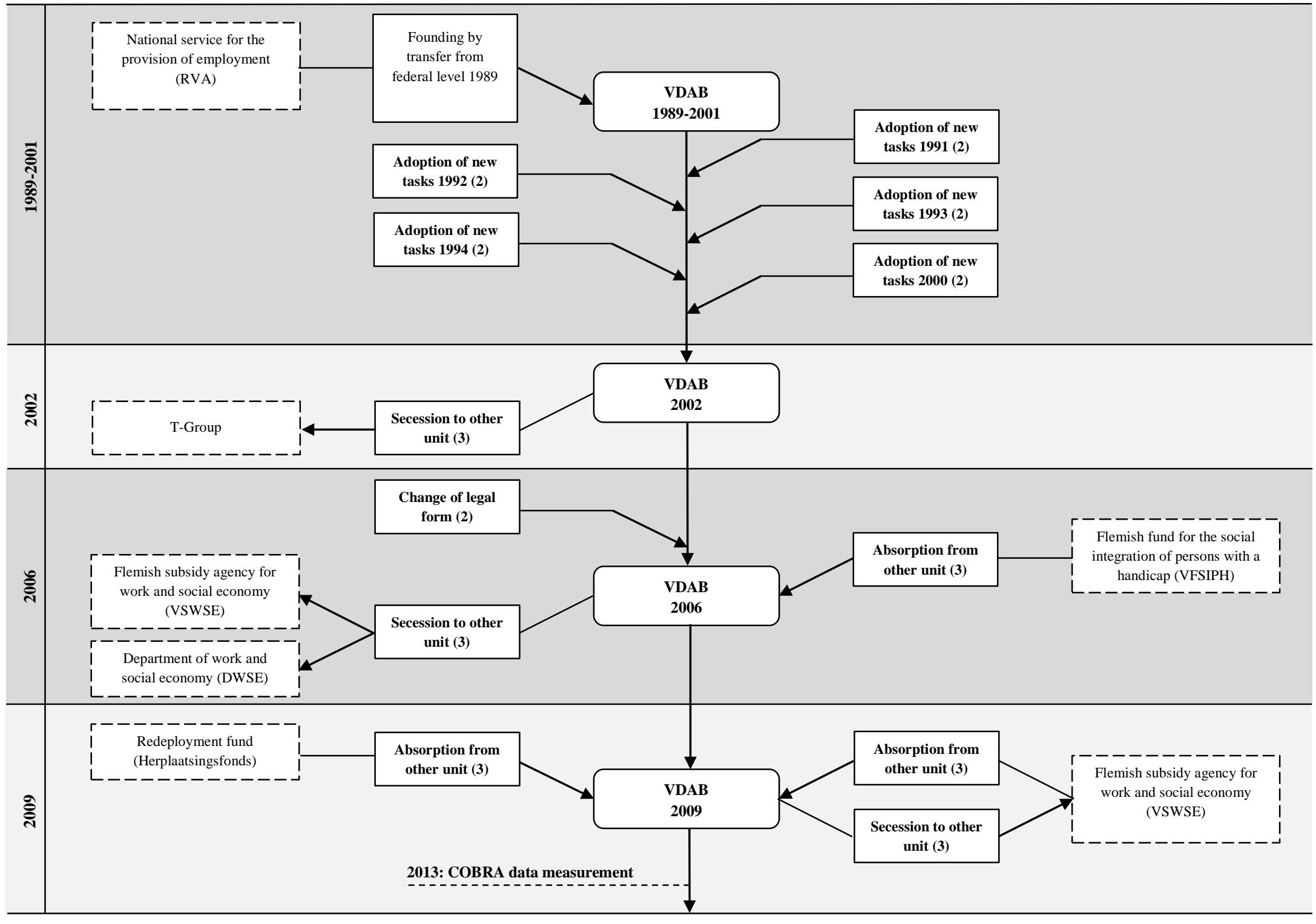


Figure 1 gives an example of a reform trajectory by zooming into the organisational history of structural reforms of the Flemish public sector organization Flemish Service for Job Mediation and Vocational Training ('Vlaamse Dienst voor Arbeidsbemiddeling en Beroepsopleiding' - VDAB). This agency under public law is notable in our sample as the organization with the most identified structural reform events and thus provides a good illustration of the various types of reforms that are coded in the BSAD.

The figure shows how in 1989 the organization is transferred to the Flemish level after a transfer of competences from the national level, which we regard as its founding moment. Subsequently, the VDAB adopts a number of new activities and tasks in the 1990's and in 2000. These include new competences to provide services and advice to employees of organizations through career guidance and outplacement (1991), the opening of 14 centres for lower educated and long-term unemployed persons (1992), the opening of 38 education centres (1993), the creation of an Ombudsman position for complaints against VDAB decisions (1994) and the VDAB's designation as Flemish coordinator for the career guidance and unemployment reduction elements of the European Social Fund (ESF3 funds) (2000). In 2002 the T-Group, up until that point a subunit of the VDAB responsible for the organization's commercial activities, has been split off from the VDAB and privatised.

The changes in 2006 were imposed in the context of the Flemish whole-of-government reform program dubbed "Beter Bestuurlijk Beleid" (Better Administrative Policy), which introduced many new single-purpose agencies by conducting a separation of policy execution tasks and policy development tasks according to the NPM model. In the context of these reforms, the already existing agency VDAB seceded units to the newly formed Flemish Subsidy Agency for Work and Social Economy (VSWSE) and the new Department of Work and Social Economy (DWSE), while receiving a section from the simultaneously reformed Flemish Fund for the Social Integration of Persons with a Handicap (VFSIPH). Moreover, as Beter Bestuurlijk 
Beleid introduced a new typology of (semi)independent agencies, the legal form of VDAB was modernized from a so-called 'institution of public interest' category B to its new analogue, an external autonomous agency under public law. In 2009 the VDAB absorbed the Redeployment fund (Herplaatsingsfonds) in its entirety and also exchanged some personnel with the VSWSE. Due to there being a time difference between the legal imposition of the VSWSE and Redeployment Fund personnel absorptions, we regard these as separate events. Thus, the events included in the BSAD illustrate a long trajectory of various structural reforms, characterized by expansions of tasks in the VDAB's early life on the Flemish level, reforms consistent with NPM in 2002 and 2006, and a cluster of absorptions and a secession in 2009. 